\author{
Dr. Ali M. AlShehri \\ Associate Professor of Linguistics \\ College of Science \& Arts in Baljurashi, Al Baha University \\ Kingdom of Saudi Arabia
}

\begin{abstract}
:
Departing from the notion that the EFL teacher is supposed to have passion for his profession, he has to explore new teaching strategies not only to do the job, but to master it as well practicing the old saw "Those who teach learn twice". Doing so, the teacher strives to change his teaching climate from being dull and monotonous into being collaborative and interactive. This change is often seen to involve three forms of knowing: knowing "that", knowing "how", and knowing "why". Infographics (as a term) is believed to have much to do with such a three-phase mode of change. This research paper addresses how infographics can be used to develop different language skills in EFL classes. The paper has four sections. Section one deals with an overview on visuality (visual communication, visual literacy, visual learning, visual language, and visual thinking). Section two tackles infographics: its definition, some theories underpinning infographics, components, types, importance, and objectives in teaching/learning contexts, and infographics in EFL contexts. Section three sheds light on some research on infographics. The paper concludes with section four which proposes a conceptual framework for using infographics in EFL classes.
\end{abstract}

Keywords: visual education, visual communication, visual literacy, visual learning, visual language, visual thinking, infographics, EFL classes, EFL skills

*Because the paper is mainly on infographics, some information and ideas in the literature reviewed must be represented graphically in order to show that infographics can be functioned in a practical way.

\title{
Introduction
}

It has been recently known that passionate education has three main components: object, person and thought. Therefore, teaching cannot be successful without an objective set to be achieved, a person to be directed to learn and a thought to be transmitted or created. What teachers in general and EFL ones in particular can do is to have the emotion to teach efficiently and effectively and to motivate their students to have the desire to learn and above all to have the right knowledge to transfer. This view is supported by Celik's (2017:87) argument that "the period we live in is a time when the students need emotional support rather than knowledge. Establishing an emotional connection with your students allow them to listen more to your recommendations, and feel these recommendations in 
their hearts". One way to reach such a destination is to provide innovative teaching strategies to EFL classes making the balance between educating the mind and educating the heart, and between enlightening the mind and shaping the heart. Infographics are seen by the researcher to do that job.

Infographics combine the process of transmitting messages including data, information and knowledge orally, in writing, or visually, and the acts of communication which are concerned with interpreting those messages and creating new meanings as well. By so doing, the visual association of the objects represented visually and their meanings can constitute a visual culture or literacy. This means that the layout with its different elements (lines, signs, colors, and relationships) and the content can function the message or the meaning intended by the infographic initiator.

Infographics can be - to the researcher's belief - a visual learning path in which learners tend to use their vision to identify data, information, and knowledge in the infographic presented, absorb it, and match it to specific mental models or mind sets. Not only can learners analyze information, criticize it, evaluate it, compare it, and contrast it, but generate new information or function it as well. Having done those processes or some of them, learners might be able to share visual information, or manage it in a more effective way, or even construct new visual information in one way or another, (Bellato, 2013; Davidson, 2014; Krauss, 2012). But the capacity to innovate new visuals depends on how far the message is necessary, how effective it is encoded visually, and how far it is important for a specific audience.

\section{Visuality: An overview}

All people - including students - communicate visually throughout the hour or even at the minute round, since that sort of communication depends mainly on vision. It is the process of transmitting ideas, data, information in two or even three dimensional visual ways including drawing, typology, graphics, graphs, figure. Even face expressions, clues, posture, appearance, personal distance, and visual symbols are involved in visual communication. In different educational settings, visual communication can be strengthened via visual input(s), which - by their turn are stored in the visual working memory. Once happened, learners might be able to reason, comprehend, and then learn. Hence, visual communication can be defined as sending and receiving visual messages, (Bamford, 2003). In order for an individual to be an effective 


\section{Dr. Ali M. AlShehri}

communicator nowadays, s/he needs to interpret, produce, and select suitable images/visuals in order to transmit a series of meaning.

Since the 21 st century is widely known as the digitalization era appealing to the visual sense more than the other ones, many terms have emerged related to visualization and visuality such as visual education, visual communication, visual learning, visual literacy, visual thinking, visual language. But no one term of them can stand alone without an endless connection with others in different paths. Visual literacy seems to be involved in all except visual thinking which steers visual literacy. Therefore, when visual literacy is developed, it enables the visually learned person to understand, interpret the visual events, visual symbols and visual images which he is exposed to in his environment, whether they are natural or man-made.

Visual literacy, consequently, is defined by Brill and Kim (2007) as the ability to read, understand, interpret and write a visual message or a language, whereas Brown (2015) defines it as a group of abilities that assist the individual to find information, interpret it, evaluate it, use it , and then create images and visual means in an effective way. These definitions stress that visual literacy skills provide the learner with the tools to understand and analyze the environmental, cultural, moral, aesthetic, intellectual, and artistic components involved in the two process of creating and using visual materials. Nearly all the definitions reviewed by the researcher ( e.g., Bamford, 2003; Brill, Kim \& Branch, 2001), besides the previously mentioned ones, revolve around the significance of visual literacy in strengthening the relationship between what is seen by the eye and what is seen by the mind. In light of this, the visual literate person is one who is able to able to discriminate and perceive the seen objects as a part of visual intelligence, construct visual objects, still or animated in an effective way on a specific scale, understand and assess the visual proofs provided by others, and get the objects seen in the eye of the mind. In addition, visual literacy has many advantages. Among them are:

1. Helping to get information and construct knowledge, and build successful educational outcomes (Fitzgerald, 1995).

2. Encouraging assessment and understanding the effective visual communication (Bamford, 2003).

3. Causing effect on people's attitudes, beliefs, values and life styles (Ausburn cited in Bamford, 2003).

In the educational context, teachers use visual representations for some purposes as Eilam (2012) proposes: (a) to have self-professional development, and (b) to enhance their students' understanding of 
concepts, processes, structures, interactions and live phenomena. Students, on the other hand, get that benefit in problem solving when handling their home assignments, taking their examinations, or in generating or finding their own visual representations in their process of learning. In order to do this successfully, some teaching objectives for visual literacy might be proposed. Students should (a) read visual messages, (b) transform the textual content into a visual one, (c) structure and save visual messages, arrange visual messages, (d) function colors in various forms, (e) find relationships between visuals, and (f) extract information from visuals and creative visual messages.

Bearing in mind that visual literacy is perceiving, understanding, interpreting, assessing, critiquing, and/or constructing visual messages, there must be certain levels for such process. For reading visuals in order to fulfill the rest of the processes, five levels can be suggested: cognition in which the learner identifies the components of the image or the visual, description where the learner describes the image or the visual in general, analyzing in which the learner analyzes the image or the visual into its composing components using his past knowledge in interpreting the image or the visual as a whole, creating where the learner functions the image or the visual components in new contexts, and composing in which the learner is supposed to write a report on that image or visual. This is supported by Matrix and Hodson (2014) when they stated that visual digital literacy skills are supported by what is called infographics.

As it is widely known that the most prevailing style of learning is the visual one, visual learners learn visually via drawings, images, graphs, pictures, and other visual forms. Therefore, visual learning which is represented by infographics seems to be a combination of data and information with graphic design as shown by Smiciklas (2012). Researchers ( e.g., Bamford, 2003; Marbella, 2014; Vaishnav (2013); Zainol Abidin et al., 2011) stress that a close relationship between visual learning and achievement exists. For this, visual teaching must be there as Bamford (2003) believes - for learners to (a) develop critical thinking skills related to visuals, (b) enhance the items and vocabularies of the textual and visual literacy enabling speaking and writing about images, (c) integrate the visual literacy in all scopes of curriculum, (d) ensure that there is some sort of a balance between the textual literacy and the visual literacy inside the classroom, (e) encourage them to think of and critically examine the images provided, then analyze and assess the embedded values in those images. Therefore, when visuals are added to textual 


\section{Dr. Ali M. AlShehri}

material or an auditory one, basic as well as higher-order learning can take place, (Fadel and Lemke, 2008).

Bearing in mind that the visual language is a system of communication using visual elements, that communication cannot take place or specifically cannot be divorced from textual features. Therefore, the combination of both might help in functioning the visual language creatively - clarifying the ambiguous concepts, facilitating them, explicating deeper meanings, and strengthening the process of communication as a whole. Furthermore, complex ideas become easy to grasp, and different patterns in information can be clearly identified. This is the why behind the-taken-for-granted claim that all textual and visual literacies of the whole people integrate comprehensively, and visual thinking must be there when learning, communicating, or just visualizing. When visual thinking, visual cognition, visual understanding, visual analyzing, and many other processes take place, sub-processes occur , according to Diakopoulous et al. (2011): extracting perspectives for the information provided visually, producing judgments as for that information, and sharing that judgments with others. Little can , therefore , be done without infographics, the focus of this study.

Contributing to the relationship between the terms discussed above ( visual communication, visual literacy, visual learning, visual language, visual thinking ) is believed to shape the way the EFL teacher takes to reach the objectives he intends to accomplish. Below is a figure showing the levels of visuality - from the researcher's point of view as it has been reviewed. 
Figure 1. Levels of Visuality

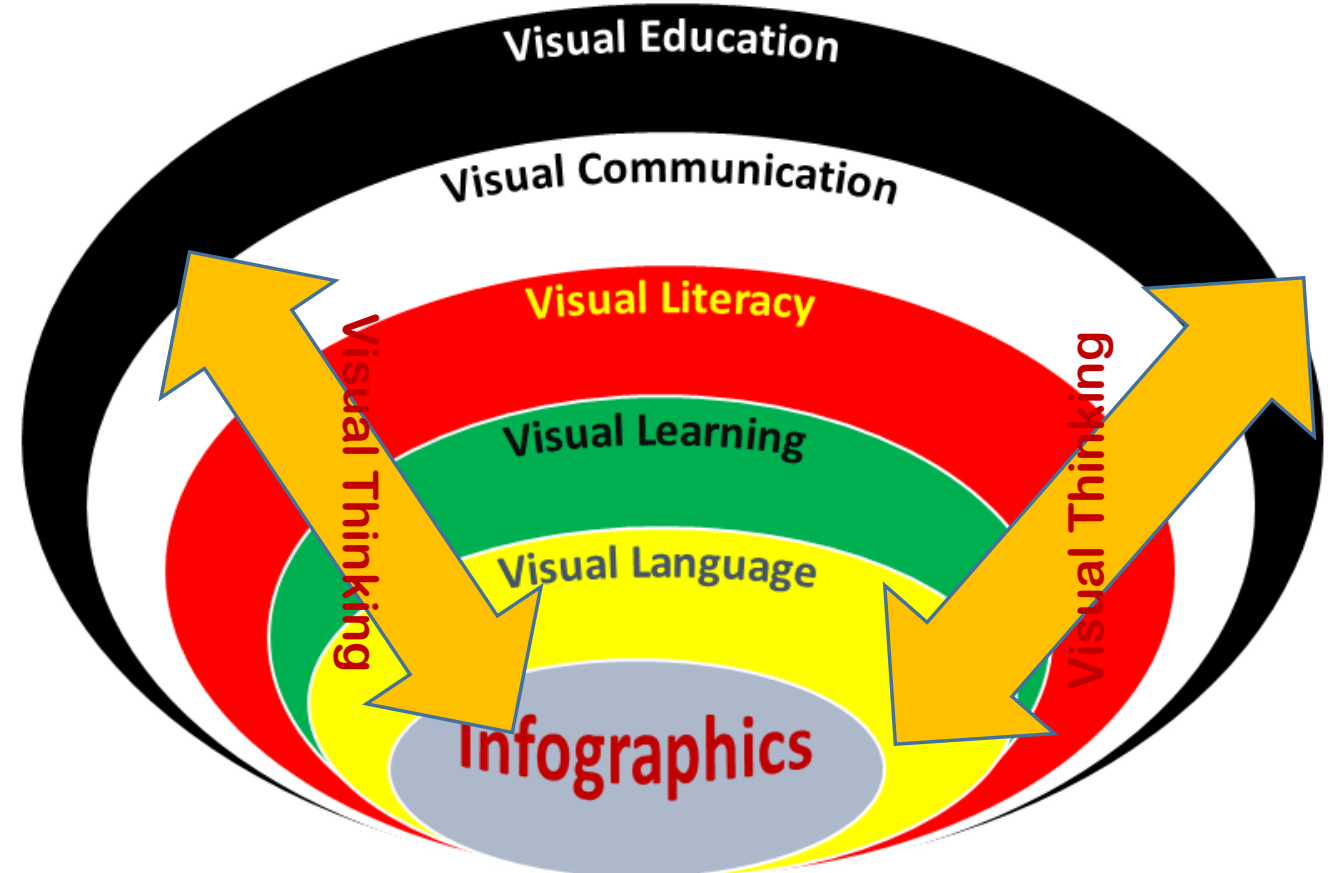

\section{Infographics}

\section{A. Definition}

Since infographics are part of information visualization as Mol (2011) states, infographics do what visualization does. This means that infographics enable comprehending data and information provided in large amounts, their features and properties as well as detecting their reliability, clarity, and accuracy. Many researchers ( e.g., Adams, 2011; Costill, 2013; Harris, 2013; McCartney, 2013; Rossow, 2013, Smiciklas,2012, Mol, 2011; Willmer, 2015) have an agreement that infographics are graphic visual representation of data, information and knowledge intended to present complex information quickly and clearly. From a linguistic point of view, Veszelszki (2014) holds the belief that infographics are information visualization. She thinks that the examination of the relationship between information visualization and linguistics has to be divided into two directions: (a) the manner and the why behind visualizing information by linguistics, and (b) whether the visuals and texts can be integrated and in what way. To other researchers, the infographic is the art of transferring information and complicated data into cartoons which are much easier for perception and recognition. It does not require reading much information and more texts which leads to effective visual interaction. This art is also called interactive data visualization and information design. It might be represented using this equation: Information + Graphic = Infographic (Shaltout, 2014) or design + writing + data $=$ infographics (Stewart and Robinson, 2015). 


\section{Dr. Ali M. AlShehri}

Operationally, in this study, infographics is the art of visualizing and transferring information and data used in programming into expressive figures which can easily understood or as it is referred to by Smiciklas (2012) and Reitz (2014) : a visual way of conveying data, information ideas and concepts in a quick, easy and exciting way. Therefore, infographics, to them, are an effective communication tool. In a public or educational setting, infographics can also be a presentation tool, ( Lema,2012). From a pedagogical point of view, Matrix and Hodson (2014) stress that the use of infographics is a pedagogical approach or a pedagogical strategy in which learners, specially the visual ones, communicate information, retain and remember it effectively. By this, infographics can be a sharing information tool that helps learners communicate information in different ways, which in turn, can inspire what it can be called peer-to-peer critique. Students, therefore, become able to have valuable reflections and insights on what their peers have provided, filter information, and develop or take positions. McCartney (2013) sees that infographics can be effective teaching tools either when planning the lesson or when delivering it inside the classroom. Through a guided discovery process, students can identify whether information the information provided is reliable or distorted, discover relationships between different pieces of information, and decide how well the information is categorized. From another perspective, Sudakov et al. (2015) defined infographics as an educational tool for teaching (when introducing new topics or giving a broad overview of new subjects, providing discussion starters, reflecting on a specific subject material provided, or explaining new concepts), for learning ( when receiving a visual representation of a specific material, communicating a wealth of information in a quick and clear way), and for assessment (when asking students to create their own infographics in order to visually show that they have grasped what has been taught to them).

Wooten and Jernigan (2015) took a linguistic path when defining infographics. They believe that infographics are a process the same as the writing process that has sub-processes: generating ideas, drafting, revising, edition, and then publishing. 


\section{Figure 2. Infographics as a Process}

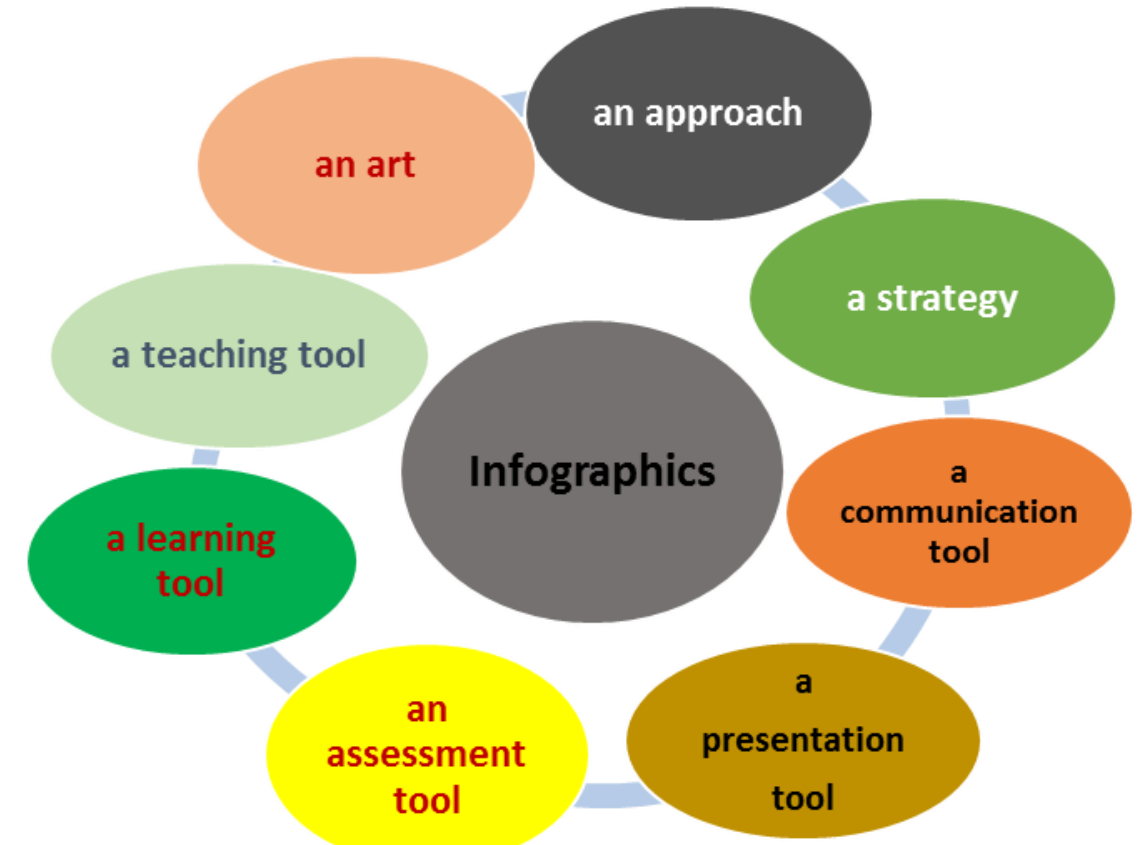

\section{B. Theories underpinning infographics}

One of the distinct features that characterize infographics, to the researcher's belief, is the theoretical breadth and depth. First, they appear to be in accordance with the cognitive apprenticeship, the instructional model proposed by Collins et al. ( cited in Abdel-Haq, 2008). To them, cognitive apprenticeship is based on guided experience that help students understand the processes involved in learning, lead them to have greater understanding of the material, and encourage them to have greater levels of knowledge retention. In infographics-based teaching situations, the teacher directs his students to make use of them as an instructional model embedded in one visual form or more that can be used in authentic activities. Students, consequently, not only can have better acquisition and recall of information from visual memory, but can transform this visual information to other situations.

The dual coding theory also seems to provide a foundational base for infographics. Since one of the two separate mental subsystems is the visual nonverbal one which specializes in visual representation, a form of knowledge storage is the imagery one involving mental pictures and the physical sensations. Hendson (cited in Hickie, 2006) asserts that treating, storing, and representing information graphically/visually can lead to form understandable mental images, and stimulate and increase the mental activity.

According to Wolfe's (2009) view, transformational learning - rooted in Mizerow's Transformational learning theory - causes a change in thinking after digesting information. Students are triggered to have 


\section{Dr. Ali M. AlShehri}

interest in their learning instead of being spoon-fed pieces of information to memorize. Via infographics, students are able to transform information into infographics and vice versa, or transform the textual language into a visual one and vice versa, or to transform the visual language from one content to another.

Information processing theory also appear to be deeply rooted in infographics. Many researchers ( e.g.,Marabella, 2014; Willis et al., 2008) stress that deep processing of information increases its recall and improves memory. When learners are exposed to visual language expressed by one or more types of infographics, more cognitive webs and mental models are generated that by their turn accelerate learning.

The cognitive load theory is another area of research that is believed to be related to infographics. The cognitive load in Sweller's (1999) belief is the whole activity that takes place in memory. The ability of the working memory is thus the most important element/ component in this theory. Whenever the cognitive load is bigger than the working memory span, meaning, therefore, comes after. Sweller classifies the cognitive load into three forms: (a) internal cognitive load that determines how far information is difficult and how far it is complex, i.e., the actual components of the information and the interactions taking place between them, (b) external cognitive load that deals with the way of displaying information, and (c) conformable cognitive load that is determined via the mental activities associated with the learning process. In infographics-led classes, all those types are there motivating the visual learning to take place since the human mind is but a gallery of visuals.

Based on those theoretical bases shown above and some others, some assumptions for this research can be stated:

a. When teachers including the EFL ones are passionate exploring new teaching strategies, they become able to motivate their students to be linguistically efficient as well as proficient.

b. Visual communication is dominating in our daily life and it is necessarily thus in EFL classes.

c. Learners tend to have the desire for experiencing new ways of learning, discovering new ways to take their responsibility of their own learning.

d. The content that is visually presented seems to stimulate active learning in which students are given the opportunity to learn better. 


\section{Can Infographics be Pedagogically Used in EFL Classes?}

Figure 3. Theories Underpinning Infographics

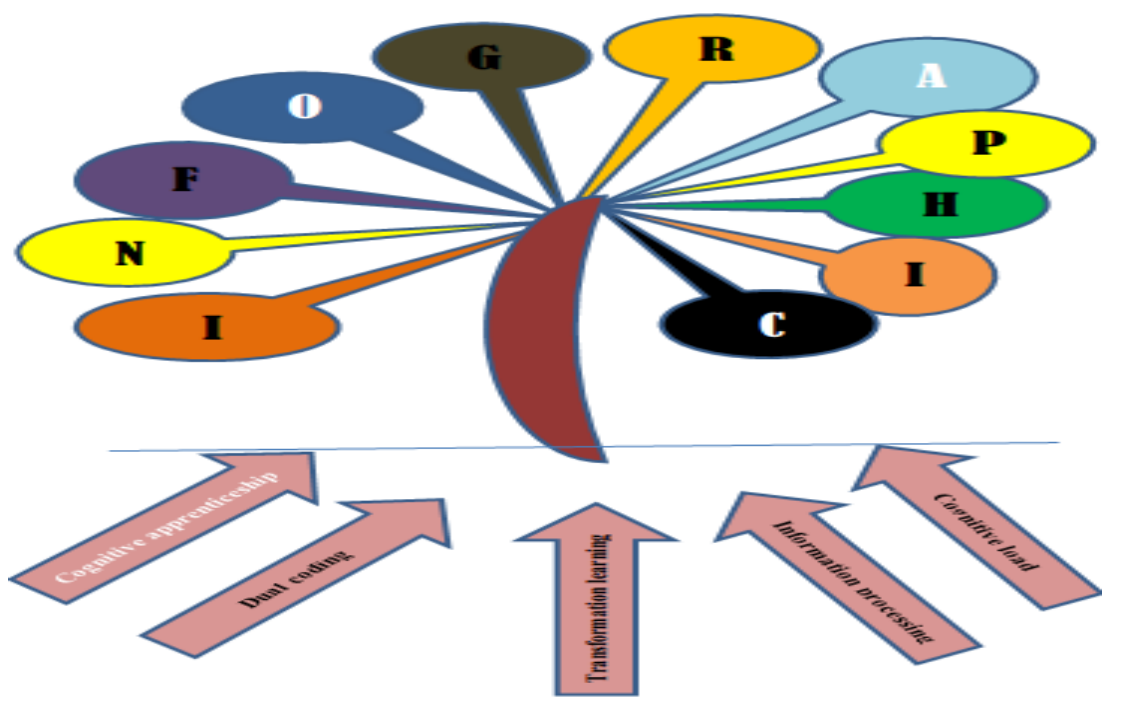

\section{Components}

The components/elements of infographics are graphically displayed from different perspectives.

Figure 4. Stewart's (2014) View of Infographics

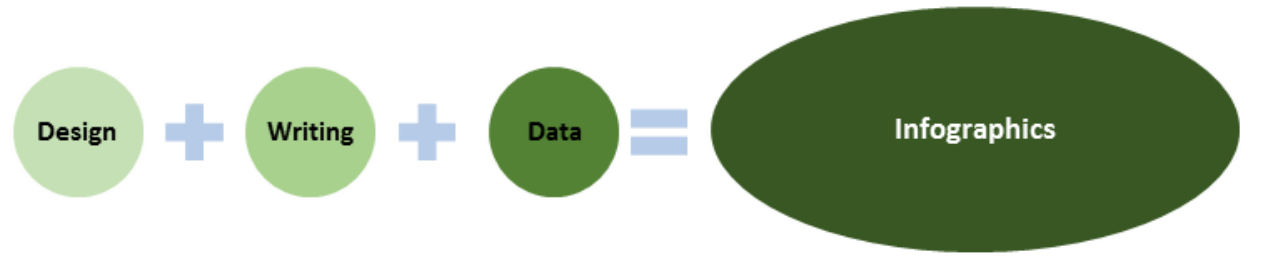

Figure 5. Shaltut's (2016) View of Infographics

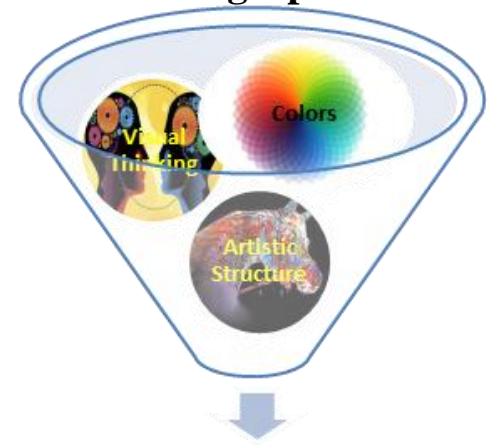

Infographics 


\section{Dr. Ali M. AlShehri}

Figure 6. Abliock \& Williams' (2014) View of Infographics as cited in Bradshaw (2015)

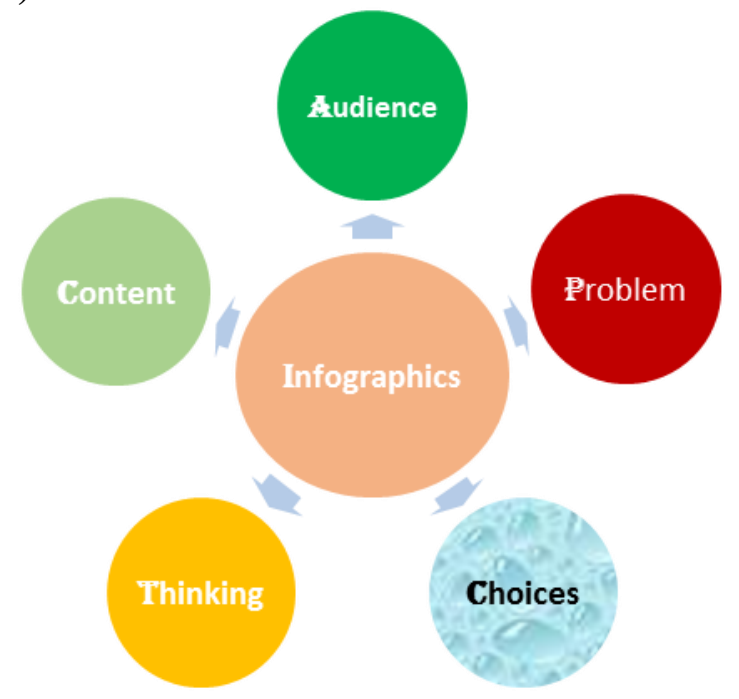

Figure 7. Adams' (2011) View of Infographics

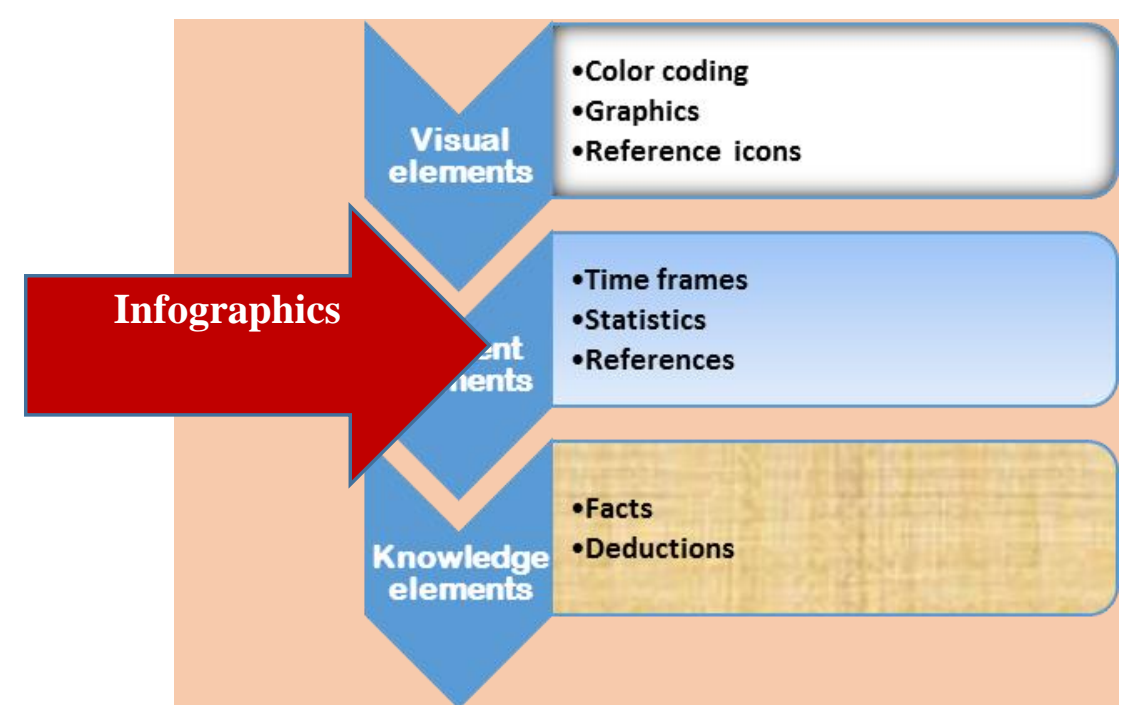

As it has been illustrated, the components of infographics are varied according to different perspectives. But no one view can stand without the other. Therefore, those who are concerned with the design and/or the use of infographics have to consider the various components according to the objective(s) they intend to achieve.

\section{Dimensions of Classifying Infographics (Types)}

Having reviewed the literature on infographics, the researcher can pinpoint the following figure as a type of infographics according to some researchers and writers ( e.g., Adams, 2011; Bloemarts, 2015; 
Huang and Tan,2007; Mol, 2011; Smiciklas, 2012; Shaltot, 2016; Stewart, 2014).

Figure 8. Different Dimensions of Classifying Infographics
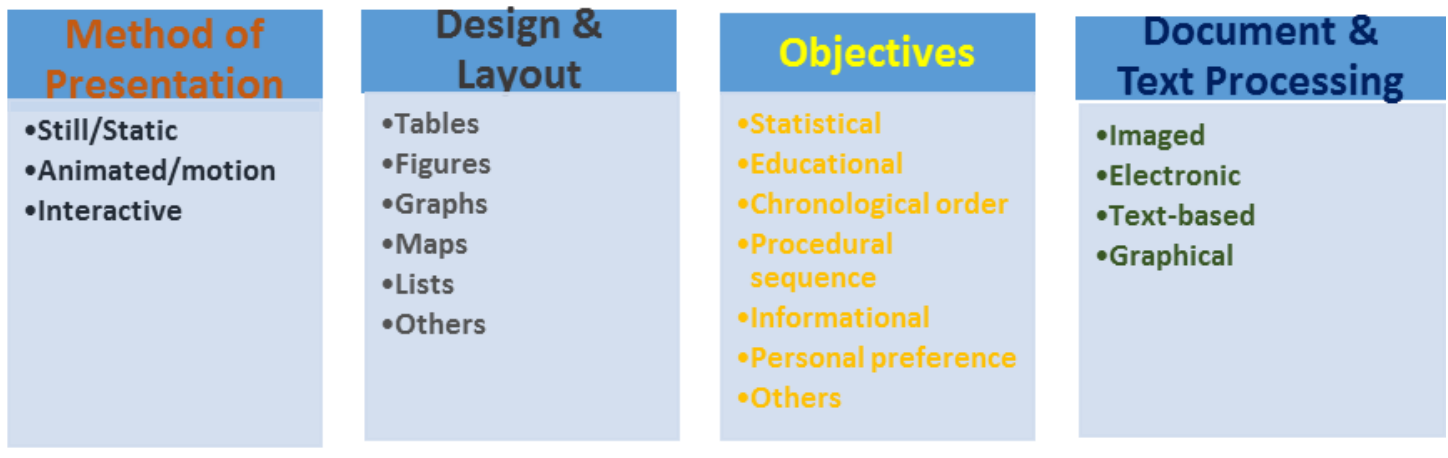

\section{E. Objectives of infographics in teaching/learning contexts}

As a teacher of EFL in Taiwan, Eisenberg (2015) sees that infographics that contain multiple layers of information, provide students with an opportunity to practice inference and interpretation, and develop their visual literacy skills. Because infographics are the main focus of visual learning, they can, according to Smiciklas (2012), (a) enhance comprehending data and information, and concepts and ideas, (b) trigger critical thinking, (c) generate new ideas and organize them, (d) better information retention and recalling. Other researchers (e.g., Bellato,2013; Davidson, 2014; de Bono,2012; Krauss, 2012; Reitz, 2012) presented other objectives behind using infographics. Since those objectives are numerous, the researcher finds it suitable to group them in figure 9 below.

Figure 9. Objectives of Infographics

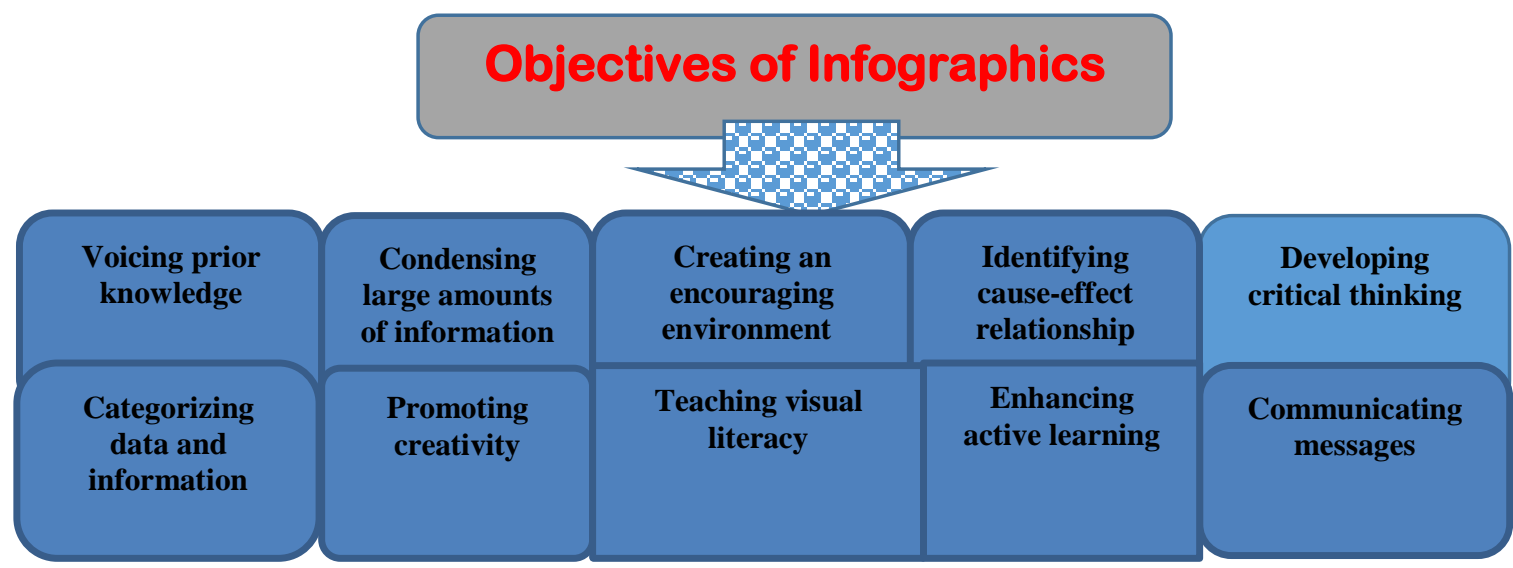




\section{Dr. Ali M. AlShehri}

\section{F. Infographics in EFL contexts}

As it has been aforementioned that good focus is directed towards using infographics in teaching and learning, EFL contexts, consequently, must take their share whether in teaching and learning the four language skills (the productive skills in particular), vocabulary, grammar, or even the functions of the language. By so doing, EFL learners can, via infographics, communicate easily, do a shared language task, give oral presentations based on specific infographics. Because infographics is still a new trend in EFL teaching and learning, only few studies have been done. In 2013, Davis and Quinn (as cited in Marabella, 2015) found that reading comprehension, writing and critical thinking skills could be improved by the use of infographics. And in 2014, Frendandez used infographics as a teaching strategy to develop critical and creative thinking. She recommended that that strategy should be used for teaching specific grammar points, vocabulary, and language functions. Following the two paths previously referred to, the researcher suggests the following exemplary infographics to teach vocabulary visually.

First: Explaining words ( verbs, nouns, adjectives, pronouns) often confused.

\section{Figure 10. Visual Vocabulary}

\section{VISUAL VOCABULARY}

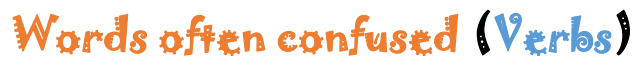
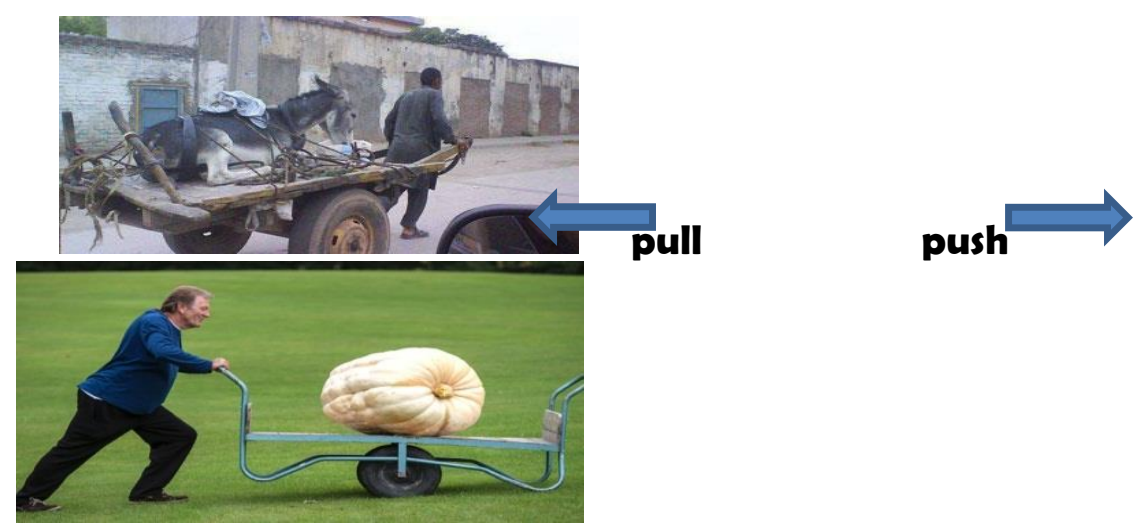


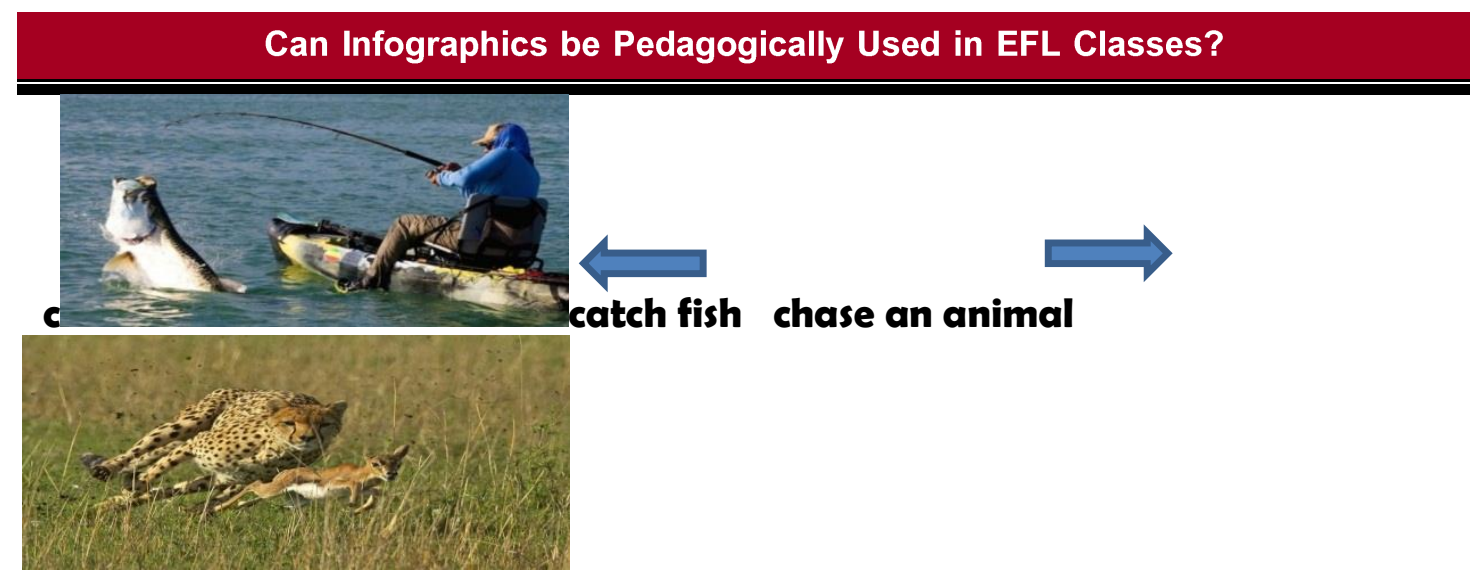

Words offen confused (Nouns)
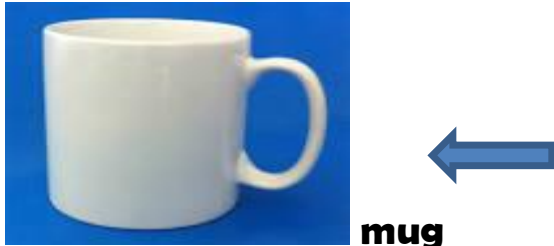

mug

cup

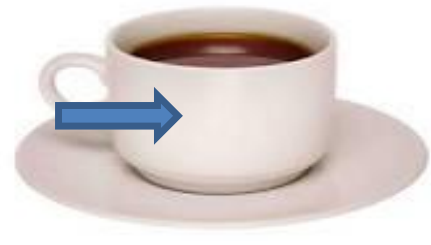

Words offan confus

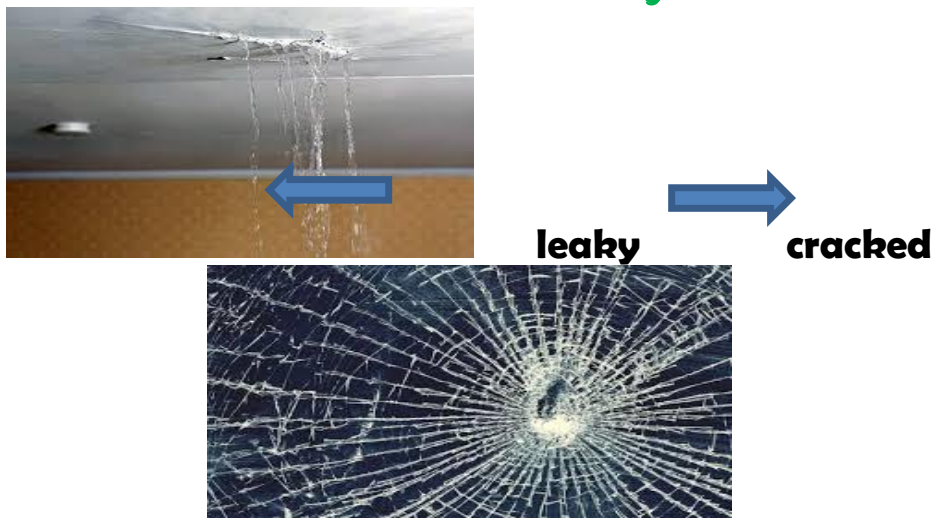

Words affen confused (Propostons)

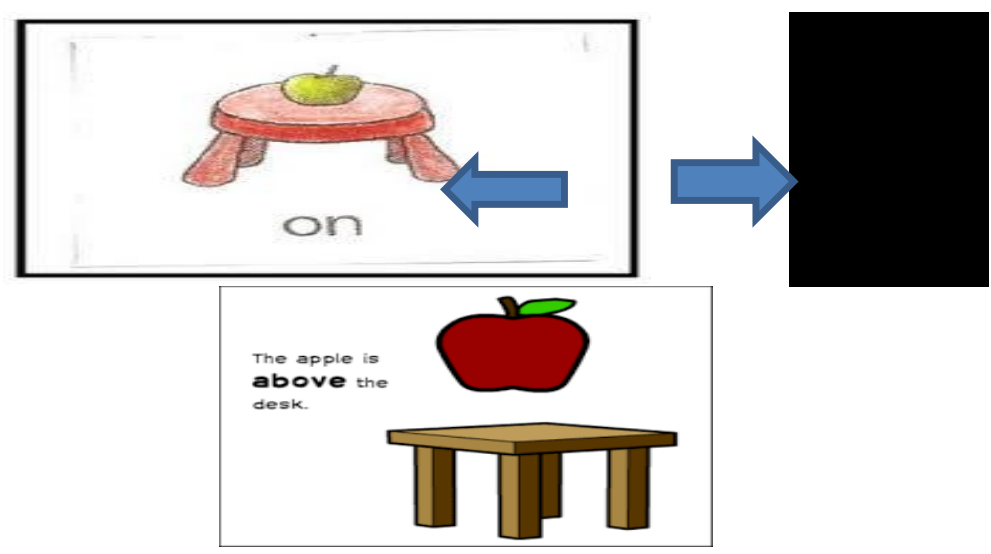




\section{Dr. Ali M. AlShehri}

Second: Showing prepositions and their relationships with objects

Figure 11. Visual Prepositions

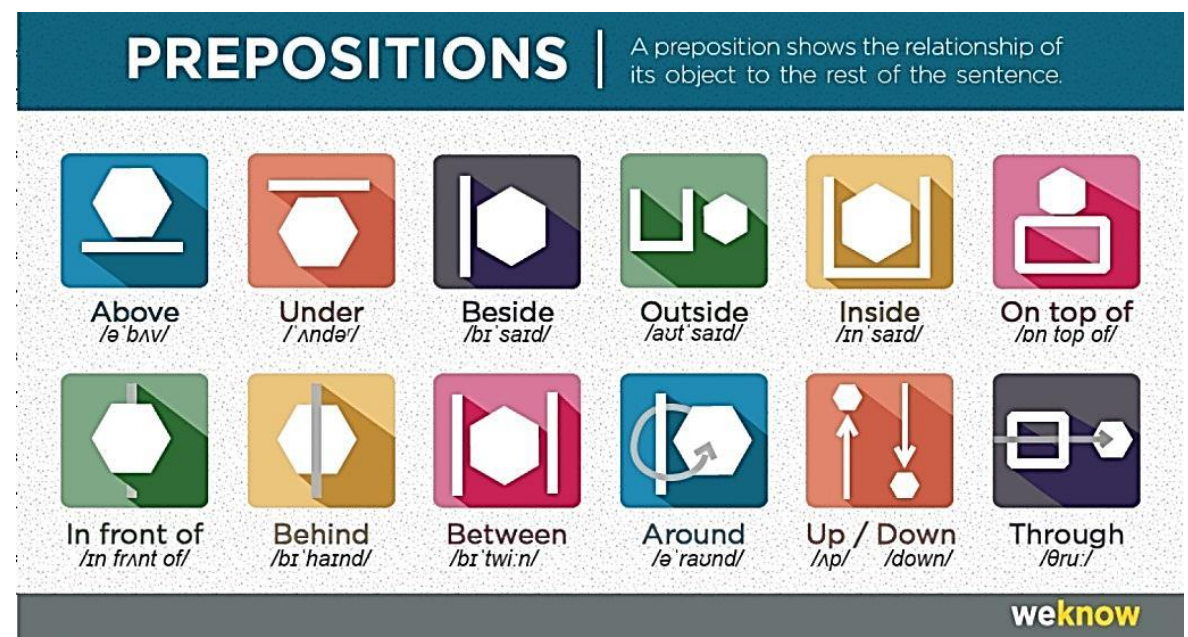

Third: Showing modality (graded)

Figure 12. Visual Modality

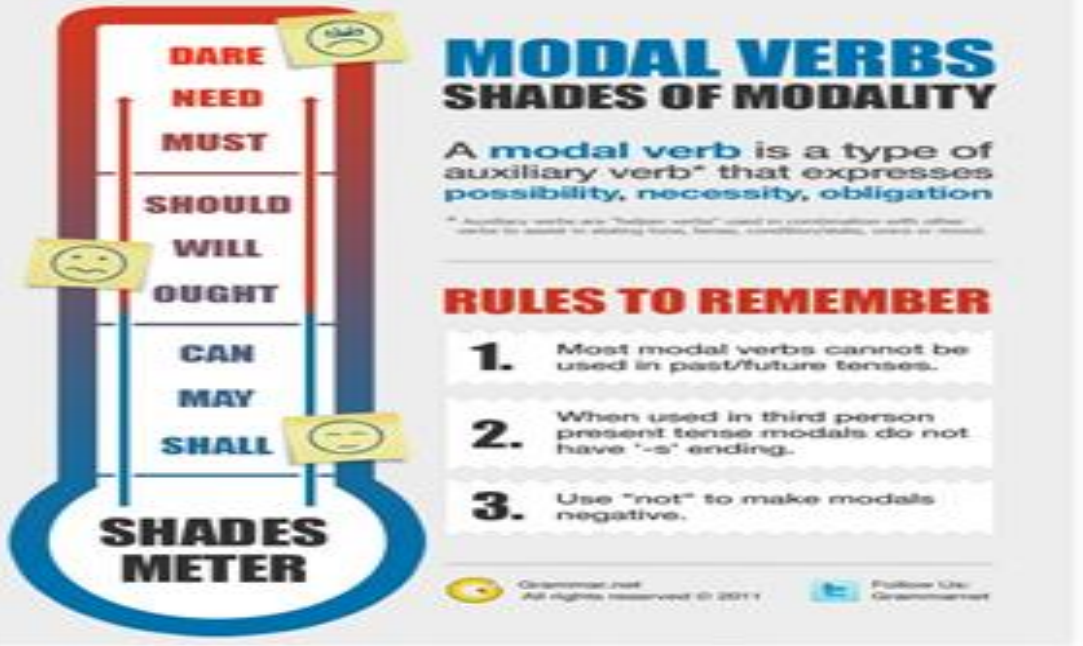

Fourth: Handling problematic grammar points

Figure 12. Visual Grammar 


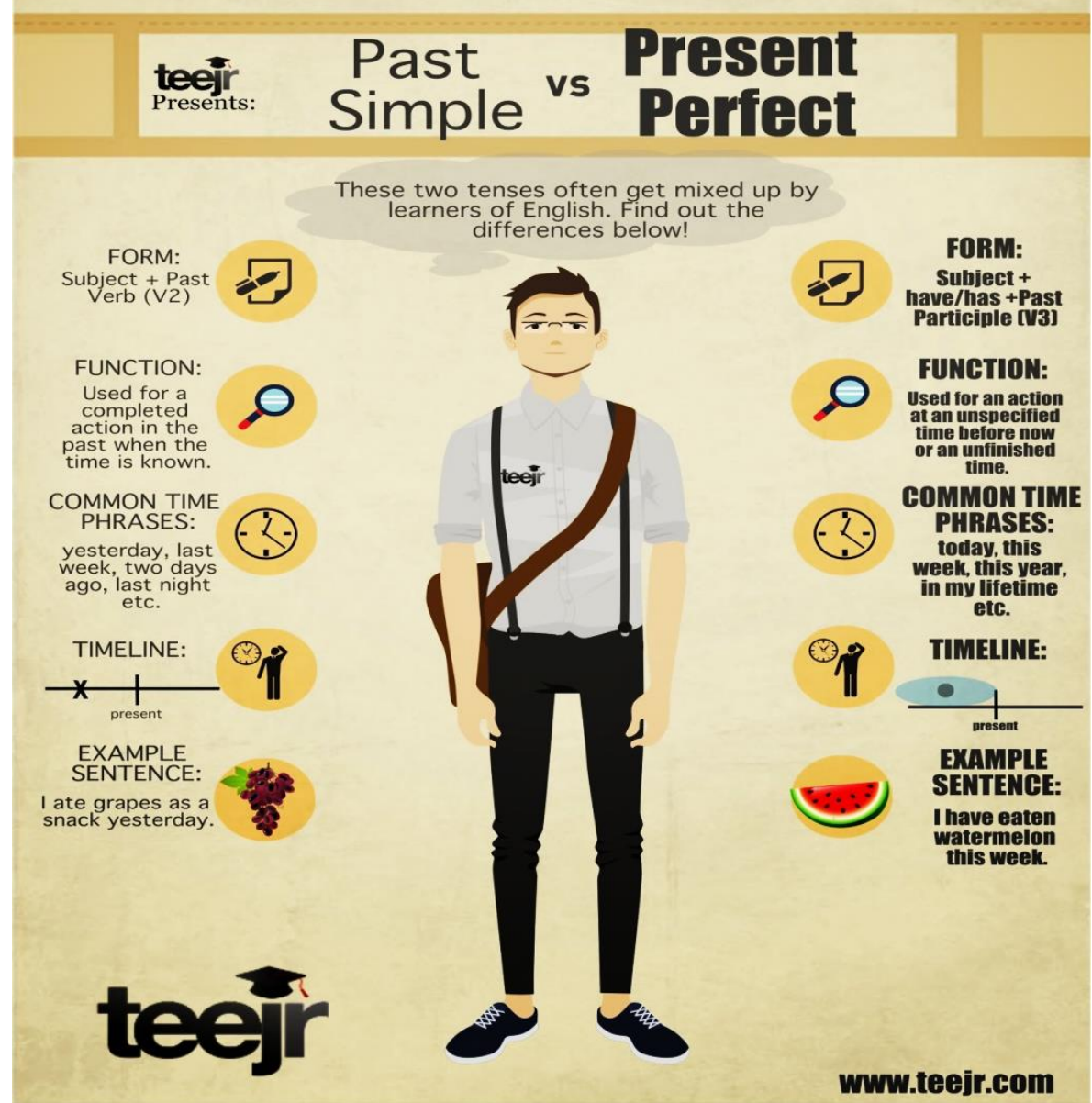

Fifth: Achieving some EFL learning outcomes ( description, classification, analyzing, comparing and contrasting, interpreting, and appreciating)

Figure 13. Visually Set EFL Learning Outcomes

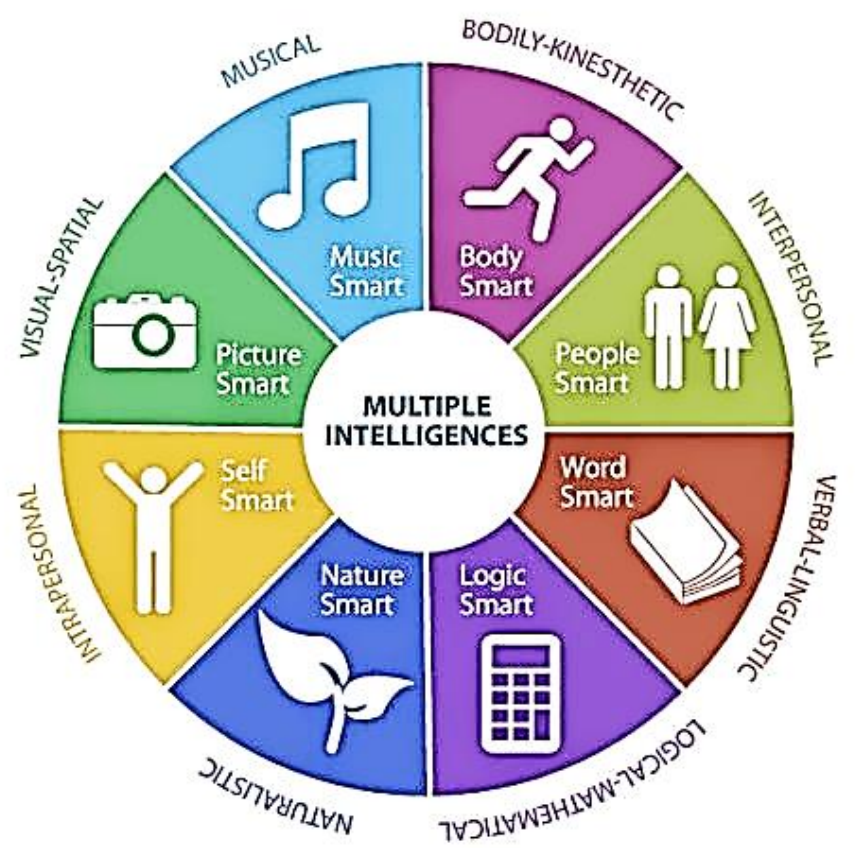




\section{Dr. Ali M. AlShehri}

Sixth: Introducing a new topic:

Figure 14. Visual Idea Expression

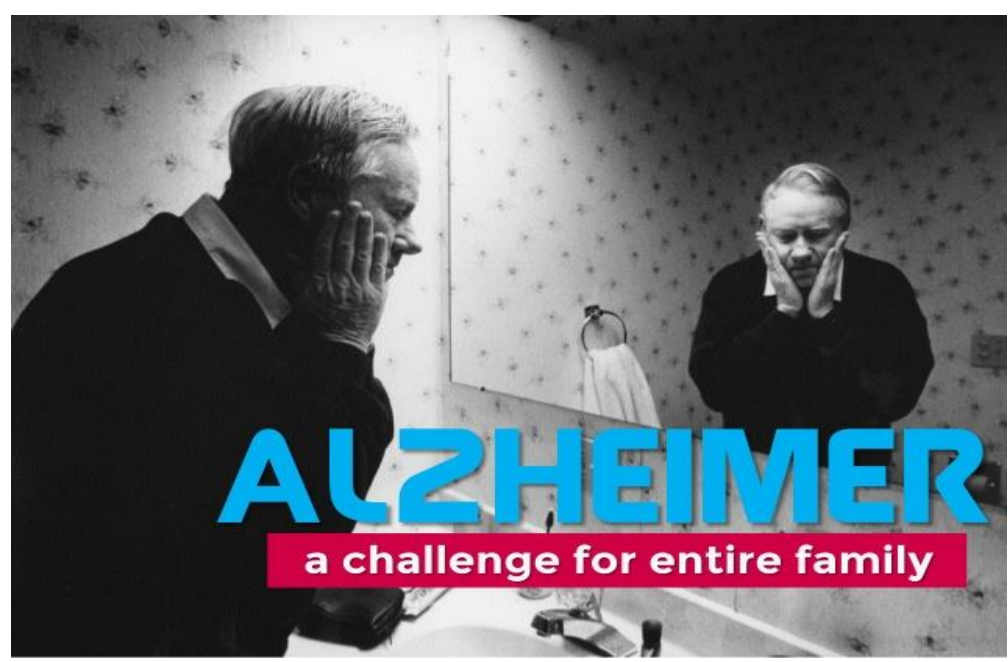

Seventh: Helping reflecting on a specific subject material provided Figure 15. Visual Reflection

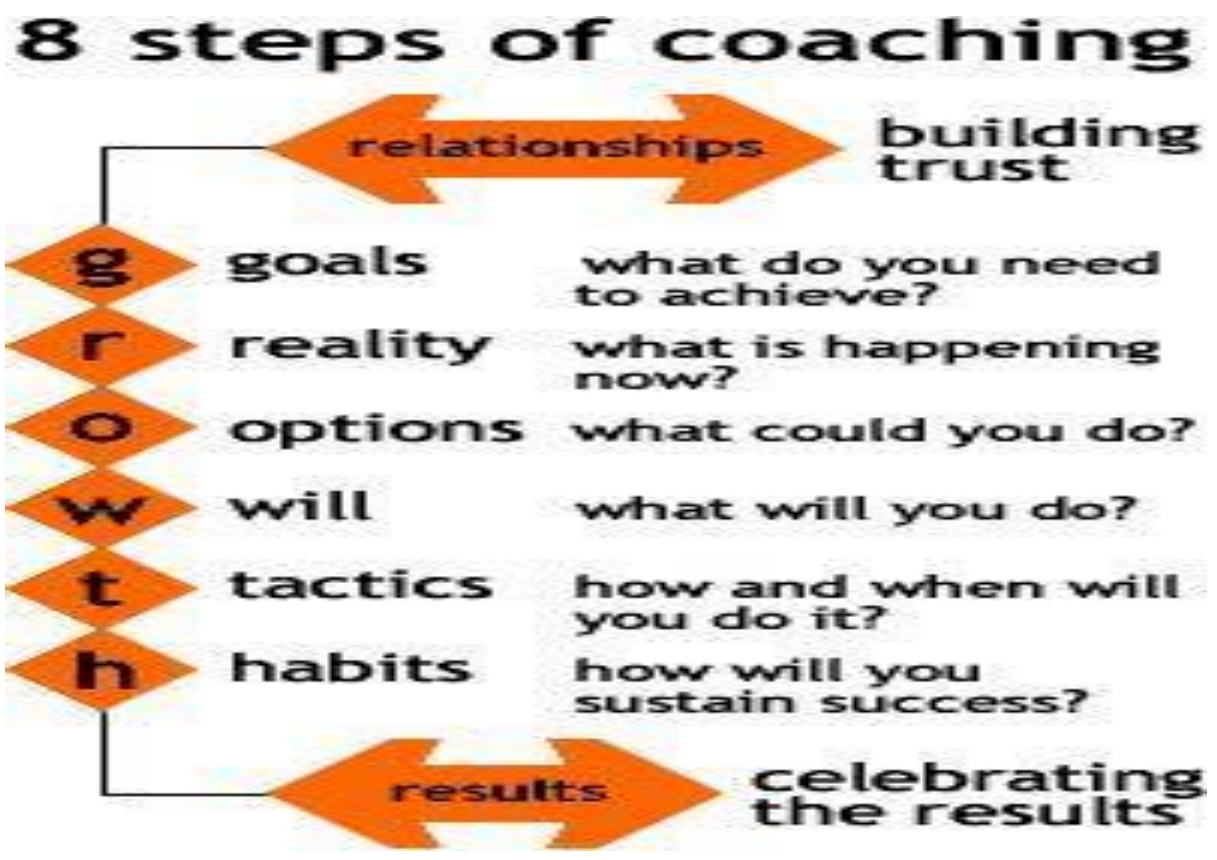

Eighth: Providing a discussion starter

Figure 16. Visual Discussion Stimulator 
Can Infographics be Pedagogically Used in EFL Classes?

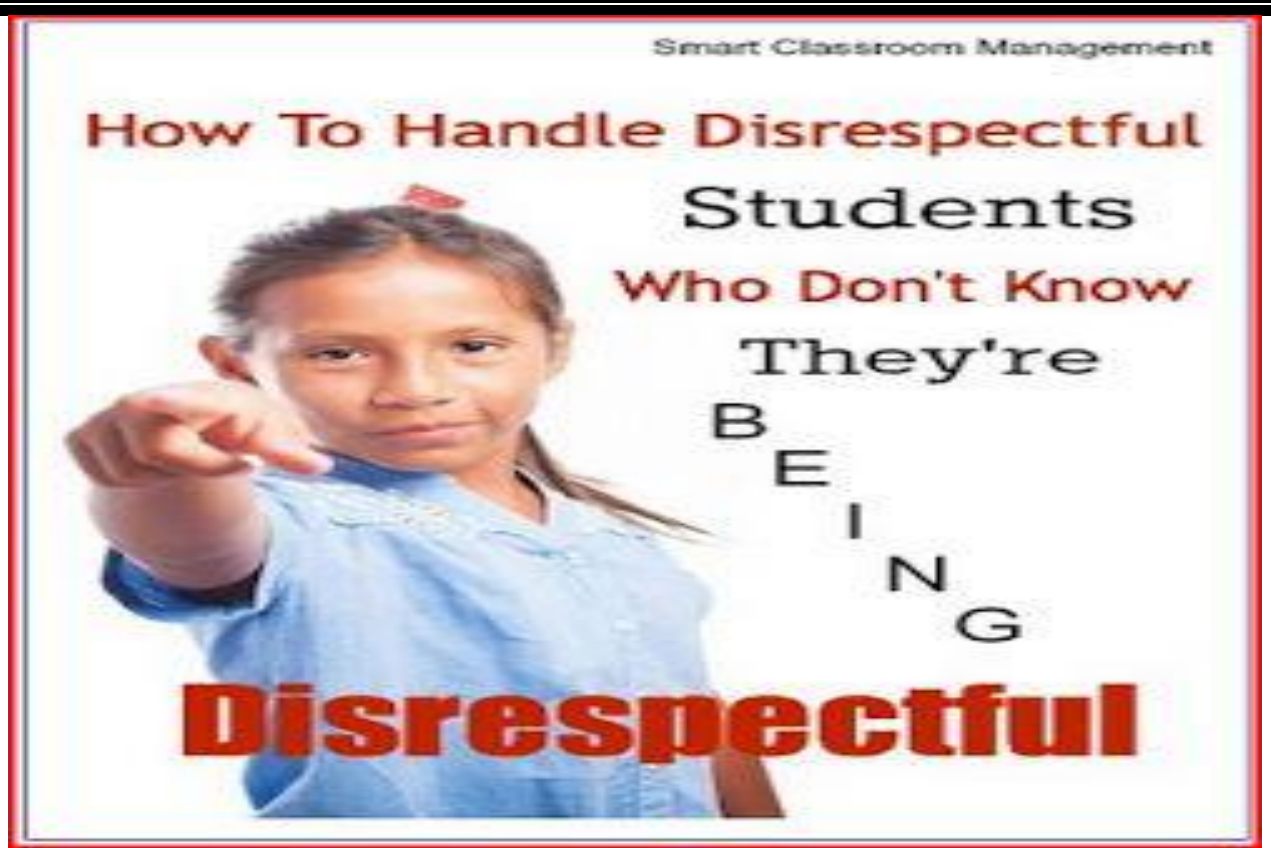

Ninth: Raising awareness of a serious problem in EFL classes

Figure 17. Visual A wareness Raising

\section{Risks from Smoking}

Smoking can damage every part of the body

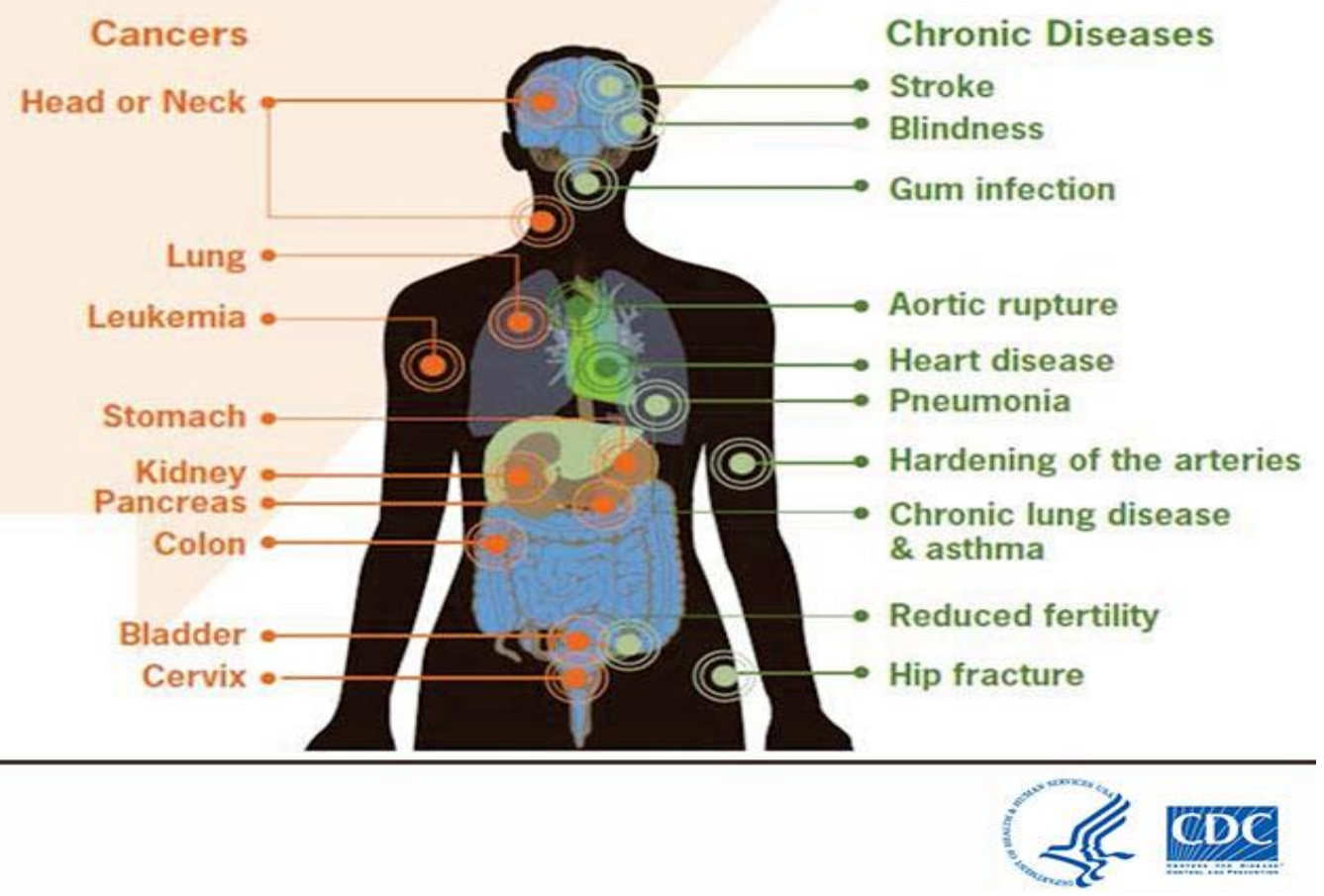




\section{Dr. Ali M. AlShehri}

\section{Research on infographics}

A review of some research that has been done in the area of infographics in teaching/learning situations is needed here:

In 2016, Al Hosni explored the effectiveness of infographics as a teaching and learning tool on EFL learners reading comprehension and memory retention. The study sample was 27 participants from two different programs in Sultan Qabus University, and formed two groups: the control group $(\mathrm{N}=14)$ and the experimental group $(\mathrm{N}=13)$. The control group used the conventional way of learning, i.e., the set textbook for reading while the experimental group used the interactive infographics to comprehend the reading texts. The mean scores on the reading comprehension post and delayed quizzes showed that the infographic group outperformed the non-infographic one in comprehension and retention memory, stressing the positive impact of infographics in EFL teaching and learning.

Al-Mohammadi (2017) proposed that infographics can be an effective visual approach to teaching programming fundamentals for developing analytical thinking skills. In order to achieve her study objective, the researcher drew her study participants $(\mathrm{N}=64)$ from a secondary school for girls in Makkah, Saudi Arabia. The control group ( $\mathrm{N}=32)$ followed the regular way of studying the Computer course, while the experimental group $(\mathrm{N}=32)$ was exposed to infographics-based teaching lessons in the same course focusing on the programming fundamentals. Results indicated the significant improvement of the experimental group's analytical thinking skills.

Zainol Abidin et al. (2011) conducted a study investigating the correlation between different learning styles and academic achievement. A number of 317 participants of various levels of achievement in different subjects participated in the study. Results showed that visual learners outperformed their counterparts (i.e., auditory, kinesthetic, global, analytic, impulsive, reflective, individual) stressing significant differences between them all favored the visual learners.

In parallel with Writer's Workshop Model, Goggins (2012) used infographics to teach writing skills to beginner writers. He displayed $6+1$ traits as standing points or standards for which they look at before handling their writings: voice, organization, ideas, word choice, sentence fluency, conventions, and presentation.

In 2014, Kibar and Akkoyunlu did a case study adopting infographics as a new approach for enhancing visual literacy skills stressing the idea that students in visual age require visual literacy skills. During the academic year 2012/2013, sixty four sophomore students enrolled in Computer Education and Instructional Technology Department 
constituted the sample of the study. The researchers required their participants to acquire instructional design skills reflected in infographics. The data were collected from the infographics designed by the participants in different dimensions shown by the rubric. It was found out that page layout, visualization, fonts and colors scored higher percentages than title, elements, and organization of information. It was recommended that students should receive more practice on analyzing infographics in order to better their performance in the visualization phase.

Matrix and Hodson (2014) used infographics as a teaching assignment. They taught college students at two different institutions incorporating infographics into online and blended coursework. Results showed that students of various academic backgrounds could benefit from infographics personally and academically, and had become visually literate.

In sum, infographics can be used pedagogically in different educational contexts, using them in EFL classes will not be an exception. Therefore, the researcher proposes the how this can be functioned practically.

\section{A conceptual framework proposed for using infographics in EFL classes}

From a pedagogical perspective, teaching using infographics is not only transferring knowledge, but creating possibilities for its good management as well as its construction. A permanent visual communication should be there as an ongoing process that fosters visual literacy in our every day practices. Teachers in general and EFL teachers in particular should become more responsible for their roles in enhancing visual thinking. However, there are some reasons behind the absence of making use of infographics as a teaching strategy. Among them are the rote learning mode, the wrong prevailing culture that texts are better and easily acquired and recalled than the visuals, teacher's various burdens that hinder him/her from searching for innovative teaching strategies, and the false view that pictures or visuals are for fun not for learning. Therefore, it would be necessary - in this respect - to look at the various ways to see teaching and learning and examine the theoretical traditions and taken-for-granted practices since the intent is to encourage visual thinking and to provide pedagogical frameworks of rethinking teaching and learning. Thus, the proposed framework of EFL classes based on infographics might have the following procedures for their implementation.

Whether EFL teachers create their own infographics or borrow some from wherever or even adapt some to the current situation in what's 


\section{Dr. Ali M. AlShehri}

called the art of collage in order to use in their EFL classes, they can use what researchers suggest as S.O.L.E. whereas:

- S represents Subject/story, and is investigated by the question: What is the subject or the story of the infographic?,

- O represents the objective(s) to be achieved by the infographic, and is investigated by the question: What is the objective of the infographic?,

- $\mathrm{L}$ represents the educational level targeted, and is investigated by the question: What is the educational level targeted by the infographic?, and

- E represents the desired effectiveness of the infographic, and is investigated by the question: How effective is the infographic in achieving the educational objectives set?

2. EFL teachers are to design and implement instruction that is consistent with goals and objectives taking into consideration that self-directed visual learning is encouraged by: (i) providing different types of infographics, (ii) handling different language skills visually, (iii) encouraging authentic feedback as for the infographics displayed to see how far they are effective in achieving the intended learning outcomes set beforehand, and (iv) helping students design and use infographics for self-learning or as a strategy for self-study.

3. Conducting mini informal training workshops for EFL students in order to help them get acquainted with different levels of visuality and how visual learning can be enhanced in different learning situations, fostering their visual memory.

Such a proposal might go in parallel with the mainstream of EFL course(s) for different educational levels without interrupting the timetables or violating the institution regulations. Just before the beginning of the implementation process, both teachers and the administration of the institution should make sure that students are aware of the role of infographics in teaching, learning and assessment. This helps them specify the workshop rationale and its requirements in the instructional context with the instructional objectives, materials needed and activities proposed; and then indicates the assessment procedures that would take place in instructional setting as well as actual classroom settings. 


\section{Conclusion}

The review of literature and its analysis clearly show evidence and provide support for the invaluable use of infographics in teaching learning contexts. Seeing infographics as an art, an approach, a trend, a teaching/learning or even an assessment tool or a strategy makes it possible to function infographics in EFL classes. They make EFL students more deeply motivated, active participants and self-reflecting the relationship between the graphics and the data or information they present, or the message they convey since those students, like other people are daily encountered by unlimited numbers of various, different visuals. Researchers and teachers might therefore reconsider the importance of injecting infographics in their teaching EFL skills in order to give opportunities for visual learning to prevail in this visual era. 


\section{Dr. Ali M. AlShehri}

\section{References}

- Abdel-Haq, E.( 2008). Cognitive apprenticeship: implications for teaching EFL reading comprehension skills. Benha Faculty of Education Journal, 18(76), pp. 1-31.

- Adams, D. (2011). What are infographics and why are they important? Retrieved from: www.instantshift.com/2011/03/25/what-are-infographics-and-whyare-they-important/

- Al Hosni, J. (2016). The power of image in English language teaching. The Journal of Teaching English for Specific and Academic Purposes, 4(1), 229-235.

- Al-Mohammadi, N. (2017). Effectiveness of using infographics as an approach for teaching programming fundamentals on developing analytical thinking skills for high school students in the city of Makkah in Saudi Arabia. Global Journal of Educational Studies, 3(1), 22- 42.

- Bamford, A. (2003). The visual literacy white paper. Art and Design. University of Technology. Sydney, Australia.

- Bellato, N. (2013). Infographics: A visual link to learning. ELearn,12(1).

- Bloemarts, S. (2015). Using infographics in class. Education Journey : Learning through Technology. Retrieved from : www.coetail.com

- Bradshaw, M. (2015). Nightingale's Novelty: Nursing infographics for the 21st century. Rutgers School of Nursing. Personal contact (email: bradshmo@sn.rutgers.edu)

- Brill, J. and Kim, D. (2007).Visual literacy defined - The results of a Delphi study: Can IVLA (Operationally) define visual literacy? Journal of Visual Literacy, 27 (1),47-60.

- Brown, N. (2015). 7 things you should know about visual literacies. EDUCAUSE Learning Initiative: ACRL Visual Literacy Standards. Available at: http://acrlvislitstandards.wordpress.com.

- Celik, B. (2017). Teaching profession and passion. International Journal of Social Sciences \& Educational Studies, 4(2), 85-92.

- Costill ,A. (2013). 6 benefits of using infographics. Retrieved from: www.searchenginejournal.com/6-benefits-usinginfographics/70917/

- Davidson, R. (2014). Using infographics in the Science classroom: Three Investigations in which students present their results in infographics. The Science Teacher, 18(3),38.

- De Bono, E. (2012). Inside the classroom, outside the box! Creating and using infographics in the elementary classroom.: Retrieved 
from:

http://insidethe classroomoutsidethebox.wordpress.com/2012/08/12/creating-andusing-infographics-in-t\&\#8230;[...]

- Diakopoulos, N.; Kivran-Swaine, F, and Naaman, M. (2011). Playable data: Characterizing the design space of game-y infographics. ACM May 7-11, 2011. Vancouver, BC, Canada.

- Eisenberg, J. (2015). Using infographics in the classroom to teach visual literacy. Retrieved from: blog.leeandlow.com

- Eilam, B. (2012). Teaching, learning and visual literacy: The dual role of visual representation. New York: Cambridge University Press.

- Fadel, C. and Lemke, C. (2008). Multimodal learning through media: What the research says. Personal contact ( email: cfadel@cisco.com).

- Fernandez, A. (2014). Using infographics in EFL classroom. Retrieved from: learnerfirstdiary.com

- Gaikwad, V. (2013). The Impact of a Visual Approach Used in the Teaching of Grammar When Embedded into Writing Instruction: A Study on the Writing Development of Chinese First Year University Students in a British University in China. Unpublished PhD thesis in Education. University of Exeter.

- Goggins, H. (2012). Using infographics in the classroom. Retrieved from: easel.ly.com

- Harris, S. (2013). 5 important principles of effective infographics. Search Engine Journal: Alpha Brand Media. Retrieved from : searchenginejournal.com/5-important-principlels-ofinfographics $/ 65085$

- Hickie, K. (2006). An examination of student performance in reading language and mathematics after two year of thinking maps implementation in three Tennessee schools. Unpublished Doctoral Dissertation, Department of Educational leadership and policy analysis, East Tennessee State University.

- Huang, W. and Tan, C. (2007). A system for understanding imaged infographics and its applications. Personal contact (email: tancl@comp.uus.edu.sg)

- Kibar, P. and Akkoyunlu (2014). A new approach to equip students with visual literacy skills: Use of infographics in education. European Conference on Information Literacy (ECIL). Hacettepe University Faculty of Education: Computer Education and Educational Technology. Dubrovnik, Croatia. 


\section{Dr. Ali M. AlShehri}

- Krauss, J. (2012). Infographics: More than words can say. Learning \& Leading with Technology, 39 (5), 10-14.

- Lema, C. (2012). Presentations using infographics. Retrieved from:http://chrislema.com/wpcontent/uploads/2012/05/stickyTeachingPoster.pdf

- Marabella, A. (2014). Communication theories: An infographic development project. Master of Arts in Professional Communication.

- Matrix, S. and Hodson, J. (2014). Teaching with infographics: Practicing new digital competencies and visual literacies. Journal of Pedagogic Development, 4(2), 1-19. Retrieved from: https://www.beds.ac.uk/jpd/volume-4-issue-2/teaching-withinfographics

- McCartney, A. (2013). How to turn infographics into effective teaching tools. Blog Home. Retrieved from: blog-visual.lu/how-toturn-infographics-into-effective-teaching-tools/

- Mol, L. (2011). The potential role for infographics in science communication. Master Thesis Communication Specialization. Vrije Universiteit Amsterdam.

- Reitz, E. (2014). Infographics in the classroom. Retrieved from: http://opiuno.wordpress.com/author/erinkingreitz/page3/

- Rossow, P. (2013). A Primer on Infographics in the classroom. Retrieved from : www.teachthought.com/literacy-2/a-primer-oninfographics-in-the-classroom/

- Sacopla, Ma. And Yangco, R. (2016). Infographics: Effects on student coding skills and conceptual understanding in Biology. The Asian Conference on Education 2016, Official Conference Proceedings. The International Academic Forum (iafor), www.iafor.org

- Shaltot, M. (2016). Infographic: From planning to production. ASAS Advertising: Riyadh, Saudi Arabia (in Arabic).

- Smiciklas, M. (2012). The power of infographics. Using pictures to communicate and connect with your audiences. Indiana: Pearson Educational Inc.

- Stewart, M. and Robinson, L. (2015). Infographics e-volving instruction for visual literacy. Retrieved from: uofginfographics.wordpress.com. 
- Sudakov, I.; Bellsky, T.; Usenyuk, S. and Polyakova, V. (2014). Mathematics and climate infographics: A mechanism for interdisciplinary collaboration in the classroom [phics.edu.ph]. Retrieved from: arvix.org/pdf/1405.6435.pdf/

- Sweller, J.(1994). Cognitive Load Theory, learning difficulty and instructional design . Learning \& Instruction , 4 , 295-312.

- Vaishnav, R. (2013). Learning style and academic achievement of secondary school students. Voice of Research, 1 (4), 1-4.

- Veszelszki, A. (2014). Information visualization: Infographics from a linguistic point of view. Personal contact $($ email: veszelszki.agnes@gmail.com).

- Willis, J. ; Jost, M. and Nilakanta, R. ( 2008). Qualitative research methods for education and industrial technology. Charlotte: IAP.

- Willmer, R. (2015). Making data more engaging using infographics. Safe States Annual Meeting, EDC: Learning Transforms Lives.: ChildrenSafteyNetwork.org

- Wolfe, C. ( 2009). Mezirow's transformational theory. Retrieved from: www. Associatedcontentcon/article/1584683/mezirowstransformational-learning.html

- Wooten, R. and Jernigan, S. (2015). Getting Googly with infographics. Retrieved from: http://docs.google.com/presentation/d/

- Yildirimi, S. (2017). Approaches of designers in the developed educational purposes of infographics' design processes. European Journal of Education Studies, 3 (1),248-284.

- Zainol Abidin, M.; Rezaee, A.; Abdullah, H. and Singh, K. (2011). Learning styles and overall academic achievement in a specific educational system. International Journal of Humanities and Social Science, 1(10), 143-152. 